\title{
Construyendo alternativas sustentables al capitalismo y a sus crisis permanentes: El caso de organizaciones indígenas campesinas de Cuetzalan del Progreso
}

\section{Building sustainable alternatives to capitalism and its permanente crises: The case of indigenous peasant organizations of Cuetzalan del Progreso}

\section{Construindo alternativas sustentáveis ao capitalismo e suas crises permanentes: $\mathbf{O}$ caso das organizacoes camponesas indígenas de Cuetzalan del Progreso}

\author{
Wuendy Armenta ${ }^{a}$ y Erika Carcaño ${ }^{b}$ \\ a Universidad Autónoma Metropolitana \\ asuetarmenta@hotmail.com - https://orcid.org/0000-0002-8106-4377 \\ ${ }^{\text {b } U n i v e r s i d a d ~ d e ~ G u a n a j u a t o ~}$ \\ erikacarcano@gmail.com - https://orcid.org/0000-0002-4097-0891
}

\begin{abstract}
RESUMEN
El documento presenta un análisis de la manera en la cual las organizaciones indígenas campesinas ubicadas en Cuetzalan del Progreso han hecho frente a los avances de la acumulación de capital, construyendo alternativas sustentables que se relacionan con la gestión del territorio. El análisis se sustenta en el trabajo de campo realizado por las autoras, así como de revisión documental. El documento se desarrolla desde las perspectivas de la Nueva Ruralidad Comunitaria y desde la Economía Ecológica Radical. Finalmente se destacan los atributos y capacidades sociales que los maseual han ido desarrollando a través del tiempo y que les permiten generar alternativas al capitalismo.
\end{abstract}

\begin{abstract}
The document presents an analysis of the way in which the indigenous peasant organizations located in Cuetzalan del Progreso have face the advances of capital accumulation, building sustainable alternatives that are related to the management of the territory. The analysis is based on field work carried out by de authors, as well as a documentary review. Perspectives are raised form the New Community Rurality and from the Radical Ecological Economics. Finally, it is concluded by highlighting the social attributes and capacities that the maseual have developed over time and that allow them to generate alternatives to capitalism.
\end{abstract}

\section{RESUMO}

O documento apresenta uma análise da maneira como as organizações camponesas indígenas localizadas em Cuetzalan del Progreso tem enfrentado os avanços da acumulação de capital, construindo alternativas sustentáveis que se relacionam com a gestão do território. A análise e baseada em trabalho de campo realizado pelos autores, bem como em revisão documental. As perspectivas são levantadas a partir da Nova Ruralidade Comunitaria e da Economia Ecológica Radical. Por fim, conclui destacando os atributos e capacidades sociais que os maseual desenvolveram ao longo do tempo e que Ihes permitem gerar alternativas ao capitalismo. 
PALABRAS CLAVE: Territorio; organizaciones indígenas; alternativas al capitalismo.

KEYWORDS: Territory; indigenous organizations; alternatives to capitalism.

PALAVRAS CHAVES: Território; organizações indígenas; alternativas ao capitalismo.

\section{Introducción}

Desde la época colonial hasta nuestros días, los territorios indígenas campesinos han sido blanco de despojo y destrucción. En los últimos años, en México se ha dado un mayor impulso a proyectos de corte extractivista, bajo el argumento que a través de ese tipo de emprendimientos se arribará al crecimiento económico. Estos proyectos se asientan en regiones específicas con presencia de recursos naturales los cuales abastecerán la demanda de los mercados internacionales. Estas dinámicas de acumulación de capital dejan a su paso la ocupación, despojo e impactos ambientales en los territorios donde habitan comunidades indígenas campesinas.

El municipio de Cuetzalan del Progreso, en el estado de Puebla, no ha estado exento a esta envestida por parte del capital. Sin embargo, diversas organizaciones indígenascampesinas que se han ido conformado en las últimas décadas, han hecho frente a la amenaza permanente de estas dinámicas de acumulación. La capacidad social, el sistema de gobernanza y la cosmovisión que estas comunidades y organizaciones tienen, les ha permitido tener una gestión del territorio que se manifiesta en proyectos productivos, generación de excedentes y en una apropiación social de la naturaleza de forma sustentable.

El objetivo de este trabajo es el analizar los procesos de lucha, defensa y puesta en marcha de proyectos productivos y sociales de las organizaciones Tosepan Titatanisky y Maseual Siuamej Mosenyolchicauanij, así como la identificación de atributos que tienen las comunidades indígenas campesinas de Cuetzalan del Progreso que les ha permitido construir alternativas sustentables al capitalismo y a sus crisis permanentes.

El análisis del presente artículo se basó en el trabajo de campo realizado por las autoras durante sus respectivas investigaciones doctorales, así como en los estudios posteriores que hemos realizado en la zona, adicionalmente se efectuó revisión documental.

Para tal fin, el artículo está organizado de la siguiente manera: en el primer apartado hacemos un análisis del concepto de territorio y su importancia en las comunidades indígenas campesinas, posteriormente exploramos como la capacidad social en las comunidades es uno de los pilares para lograr la autodeterminación, a continuación analizamos la manera en la que la apropiación social del excedente económico permite a las comunidades indígenas campesinas invertirlo en áreas de beneficio comunitario, los siguientes apartados hacen referencia a los maseual: sus organizaciones colectivas y los retos venideros.

\section{El territorio fuente de vida}

De acuerdo a la Encuesta Intercensal de 2015 del INEGI, se estima que la población en México es de 119, 530, 753 habitantes, de éstos el 21.5\% se considera indígena. Los grupos de habla de lengua indígena están establecidos principalmente en el sur, oriente y sureste del territorio nacional: Oaxaca, Chiapas, Veracruz, Puebla y Yucatán. Estas cinco entidades concentran el 61.09\% de la población total de habla indígena (INEGI, 2020). 
En su conjunto la población indígena abarca el 13.3\% del territorio nacional (Boege, 2011). La distribución de la tierra y el tipo de propiedad está conformada por núcleos agrarios, los cuales se dividen en ejidos y en comunidades agrarias. En el país existen 32,202 núcleos agrarios de estos el 23.8\% tienen como titulares a comunidades indígenas (López, 2005; RAN, 2020). Al hacer referencia a comunidades indígenas campesinas, implícitamente reconocemos el proceso histórico de repartición de tierras en México y la relevancia de la presencia indígena en este proceso.

Cabe indicar en este sentido que mientras en un primer momento la repartición de tierra a favor de una minoría hacendada implicó una clara política de explotación para generar riqueza, para los grupos indígenas el poder "conservar" su territorio ancestral remitió a la posibilidad de mantener tradiciones valorizadas en torno a un vínculo sagrado con la "madre tierra", lo que opera -en mayor o menor medidacomo resistencia frente a la explotación y el saqueo. Por ende, para las comunidades indígenas campesinas, la manera de concebir el territorio no se reduce a la apropiación del espacio, sino en la forma en la que despliegan sus cosmovisiones (Villoro, 1999), el territorio en este sentido, constituye una fuente de recursos, medios de subsistencia y áreas geopolíticamente estratégicas, donde se manifiesta lo simbólico y lo cultural (Barkin, et al., 2009). De acuerdo con Lefebvre (1969), el territorio es, por tanto, un espacio social, político, cultural, económico, de signo y de significado, espacio que permite la vida de un grupo social por tiempo indeterminado.

El territorio proporciona los elementos materiales indispensables para la producción e intercambio de bienes necesarios para la vida (Artigas, 2012). Su conocimiento permite gestiones adecuadas para que los grupos sociales consoliden sus estrategias de permanencia. Quien controla y gestiona el territorio, controla la forma en la que se accede a los insumos que proporciona la naturaleza, es decir, el poder sobre el territorio lo ejerce aquel que crea las normas de apropiación y que puede cambiarlas en cualquier momento. Por lo que, un grupo social cuyo objetivo es permanecer en el territorio de manera indeterminada trabajará colectivamente por realizar intercambios metabólicos equilibrados con la naturaleza, a la par que busca proveerse de calidad de vida. En este sentido Toledo (2009) argumenta que los procesos de apropiación que la humanidad efectúa sobre la naturaleza deberían estar restringidos tanto por las necesidades de cada individuo, familia y/o grupo social, como por los límites naturales biofísicos.

A través de las asambleas los colectivos plantean las problemáticas que atañen al grupo social, priorizando el bien común, a la par que buscan satisfacer sus necesidades individuales o familiares (Manzo, 2011). En muchas ocasiones los intereses privados se contraponen a los intereses colectivos, sin embargo, entra en juego la negociación de los miembros de la colectividad, donde se busca convencer sobre la ruta a tomar a seguir, más allá de tomar decisiones por mayoría relativa sobre el territorio. En México, la propiedad de los territorios puede ser: colectiva (ejidal o comunal) o privada (individual o familiar). No obstante, este tipo de grupos sociales, campesinoindígenas, establecen reglas para especificar los espacios donde la comunidad puede abastecerse de manera privada y las normativas para hacer uso de los espacios denominados como colectivos. El territorio es pues, el espacio donde se desarrolla la identidad histórica de estos grupos sociales, a la par que, proporciona los insumos para la vida y crea la cultura en la cotidianidad (Martínez, 2003). Esta identidad histórica se forja mediante complejos lazos sociales, con base en la cosmovisión, el ethos y las praxis comunitarias.

\section{La capacidad social base para la autodeterminación.}

La capacidad social son los recursos intangibles que las comunidades indígenas campesinas han desarrollado a lo largo del tiempo, estos recursos se componen de 
atributos como: el conocimiento vernáculo y contemporáneo, la defensa del territorio, la solidaridad, la cosmovisión, así como el sistema de gobernanza (Barkin, et al., 2011b). Estas características determinan la forma en la cual llevan a cabo la apropiación de la naturaleza, las actividades económicas que deciden emprender, así como las decisiones para invertir los excedentes generados colectivamente.

La forma en la cual los grupos indígenas campesinas participan en la toma de decisiones responde a una forma de organización en la cual, la autoridad máxima es la asamblea comunitaria, conformada por todos los miembros de la comunidad, donde se informa sobre las problemáticas imperantes, al mismo tiempo que se participa, se consensa, se convence, se trabajan y se asumen las decisiones tomadas en colectividad. En la asamblea comunitaria se toman decisiones y acuerdos de forma consensuada, a través de la democracia directa, sobre las problemáticas que aquejan a la comunidad (Carcaño, 2013). Las problemáticas en asambleas, generalmente, consisten en hacer coincidir intereses individuales o familiares con intereses colectivos. Estos sistemas organizacionales se fundamentan en el sistema de cargos, el cual es un sistema normativo conocido como "usos y costumbres", que regula la vida comunitaria, y se conforma de responsabilidades comunitarias, que son turnadas entre los miembros de la comunidad.

De acuerdo con la Participación de la Comisión Sexta del EZLN (2015), en las asambleas se exponen todo tipo de problemáticas de interés común, desde festividades religiosas hasta acciones de defensa de los territorios. Dichas asambleas se pueden extender en el tiempo hasta que haya el consenso unánime de todos los miembros de las comunidades, pues los resultados positivos o negativos resultantes se asumirán en colectivo. Las decisiones tomadas en asamblea se materializan a través de comités, cuya labor consiste en ejecutar y/o vigilar las labores de la autoridad y el trabajo colectivo de la comunidad asignados para determinada tarea (Rodríguez, 2010). Esta capacidad social de gestión les permite autodeterminarse dentro de sus territorios para solucionar problemáticas de interés común, al mismo tiempo que permanecen inmersos el marco jurídico formal del Estado Nación (Porto-Goncalves, 2009). En el caso de México, la Constitución Política reconoce estos sistemas jurídicos indígenas ${ }^{1}$, como lo describe López y Rivas (2012) la autonomía de los pueblos es entendida como un ejercicio del derecho a la libre determinación que implica el reconocimiento de autogobiernos comunales, municipales o regionales en el marco del Estado Nacional.

Martínez (2003) hace hincapié que la participación individual o familiar de los pobladores, de un territorio en los asuntos del colectivo, sea como autoridad o en el trabajo (faena, tequio, minga entre otros nombres), es una obligación que permite el acceso a derechos comunitarios. Esta participación en los asuntos de la colectividad representa un símbolo de pertenencia, es la "cuota" necesaria para autodesignarse y ser reconocido como miembro de la comunidad. Las fiestas son la máxima expresión de la vida comunitaria, en ella se refleja la participación y el trabajo de la colectividad, al mismo tiempo que se refuerzan los lazos comunitarios.

Generalmente, este tipo de colectivos campesino-indígenas trabajan mediante sistemas de cargos arraigados en su "saber hacer", los cuales se pueden asignar por roles de género, de edad, por escalafón o rotarios (Carlsen, 1999). La participación comunitaria comienza en la niñez, comúnmente representando al núcleo familiar, los cargos como autoridad suelen no tener una retribución económica, sino una valoración social de servicio a la comunidad. Los miembros de la comunidad deben ejercer los cargos adicionalmente a sus actividades privadas, por ello la duración de estos cargos suele oscilar entre uno a tres años. Sin embargo, en el caso de México,

1 La Constitución Federal en su artículo 2º , inciso a, fracción 2ª ., indica: "Aplicar sus sistemas normativos en la regulación y solución de conflictos internos, sujetándose a los principios generales de la Constitución, respetando las garantías individuales, los derechos humanos y, de manera relevante, la dignidad e integridad de las mujeres [...]" (Diario Oficial de la Federación, 2001, citado por Aragón, 2007, p.19). 
en algunas ocasiones los cargos tienen alguna retribución monetaria proveniente de programas gubernamentales.

La autodeterminación de los pueblos es posible gracias al control y a la gestión colectiva del territorio, la cual busca emprender condiciones de vida satisfactorias para sus miembros y proveerse de espacios ecológicamente sanos (Toledo et al., 2008). En los últimos años, la lucha de este tipo de grupos sociales ha sido la defensa de sus territorios a la lógica capitalista extractivista de recursos naturales. Mientras transitan entre la incorporación temporal a la fuerza laboral capitalista y construyen alternativas económicas de desarrollo en sus comunidades. Las comunidades campesinoindígenas están enfrentando sus problemáticas y construyendo soluciones de manera explícitamente activa, utilizando sus capacidades sociales para lograr objetivos tantos individuales-familiares como colectivos (Armenta, 2016).

Mediante el intercambio de conocimientos y experiencias, tanto de manera interna como externa con grupos solidarios de otras organizaciones o colectivos, estas comunidades han sumado estrategias económicas, sociales, políticas, culturales $\mathrm{y}$ ambientales para cuidar, mantener y mejorar ecosistemas degradados por el desarrollo capitalista de finales del siglo XX y principios del siglo XXI. Así mismo, generan conocimiento encaminado a mejorar la producción y comercialización de sus cultivos y a negociar con los Estados Nación para proveerse de mejores condiciones de servicios de salud, educativos, de saneamiento, de vivienda, entre otros (Barkin et al., 2011b).

Algunas veces las comunidades campesino-indígenas aceptan los recursos técnicos, académicos, y económicos proporcionados por instancias gubernamentales o no gubernamentales, en el afán de dar solución a sus problemáticas comunitarias. No obstante, en asamblea se cuestionan las intenciones de dichos apoyos para aceptarlos o rechazarlos, a la par que, se limita la intervención externa y se adecuan los recursos de modo tal que encajen con la cosmovisión del colectivo (Beaucage, 2012; Participación de la Comisión Sexta del EZLN, 2015). El control de facto del territorio se realiza a nivel local, mediante la participación de los miembros del colectivo en la vida comunitaria (organización social), para lo cual están dispuestos a luchar, defender y reconstruir su territorio en el afán de permanecer.

\section{La apropiación social del excedente económico.}

Las actividades se desarrollan alrededor de prácticas productivas organizadas bajo una gama de conocimientos tradicionales que relacionan su cosmovisión sobre la naturaleza y que a su vez relaciona el sistema simbólico con el sistema de creencias (Toledo, 2009; Toledo et al., 2008). La producción se realiza a través de relaciones sociales no capitalistas, mediante el trabajo individual-familiar y colectivo (Barkin et al., 2011a), donde se aprovechan capacidades, recursos y satisfactores que no necesariamente producen valor económico (Baran, 1987), pero que son indispensables para su reproducción social. De acuerdo con Boege (2011), México es uno de los doce países megadiversos, pues alberga entre 60 y 70 por ciento de la biodiversidad total del planeta, la cual se encuentra inmersa en territorios ocupados por pueblos indígenas.

La diversificación productiva en el sector primario es necesaria dentro delos territorios (la milpa), porque enriquece los suelos al imitar los procesos biológicos del sistema natural (bosques o selvas). Así mismo el generar diferentes tipos de satisfactores no crea dependencia económica a un solo producto. Sus actividades productivas no son sólo agrícolas de subsistencia, como muchas veces se cree, sino que a través de su organización comunitaria y al forjarse sus proyectos de vida como comunidad, realizan actividades productivas en los otros sectores (Beaucage, 2012; Barkin et al., 2011a y 2009; Martínez, 2003; Participación de la Comisión Sexta del EZLN, 2015). 
Las comunidades indígenas campesinas no se reducen al ámbito de la producción primaria, desarrollan una amplia pluriactividad que llevan a cabo dentro y fuera del ámbito comunitario. Para De Grammont (2009), la pluriactividad en el caso mexicano puede tener dos escenarios, el primero se caracteriza por unidades campesinas pluriactivas donde la producción agropecuaria es la principal actividad económica, el segundo escenario hace referencia al trabajo asalariado que define la organización laboral de las unidades campesinas. Ya sea que incluso el primero y el segundo escenario estén intercalados, los cierto es que la pluriactividad está asociada con el bienestar y los esfuerzos que generan las propias comunidades. Cuando hacemos referencia a la capacidad social que tienen las comunidades resaltamos que la pluriactividad tiene que ver con el desarrollo de las fuerzas productivas comunitarias, así como la diversificación productiva que llevan a cabo a través de la producción, circulación y el intercambio de bienes y servicios. Tal es el caso de la fabricación de diversos productos, algunos de los cuales tienen la denominación de orgánicos.

Las estrategias que han llevado a cabo para el intercambio de sus productos en muchos casos se dan a través de redes de apoyo y de economías solidarias, que traspasan las fronteras nacionales, en las cuales se negocian precios justos. Se tienen documentados casos exitosos de comercialización de sus productos a nivel nacional e internacional (Barkin et al., 2011a).

El grado de integración o desfase de estos procesos con las lógicas de acumulación capitalista determinará en gran medida los alcances de la autonomía financiera y política. Así, por ejemplo, las remesas por migración pueden o no contribuir a la diversificación de la esfera productiva de la comunidad en función del grado del ethos comunitario alcanzado (Barkin et al., 2009, p. 13).

Un aspecto que es importante destacar es que la organización comunitaria que les permite estas pluriactividades da cabida a la generación y apropiación de excedentes de forma colectiva, esto tiene implicaciones al interior de la comunidad, ya que estos podrán ser destinados a la reinversión productiva o en la inversión en infraestructura que sirve para mejoras de la comunidad (Armenta, 2016; Carcaño, 2013; Núñez, 2010; Escobar, 2009). En algunos casos, las construcciones de los servicios comunitarios se forjan, como ya mencionó en párrafos precedentes con la ayuda de apoyos gubernamentales, de organismos no gubernamentales o de instituciones académicas, que proporcionan parte del recurso pecuniario, la asistencia técnica o sólo los permisos para su realización.

En la formulación de proyectos comunitarios, el trabajo colectivo es fundamental para la consecución de los objetivos planteados, a través de las asambleas comunitarias se asignas las tareas a cada uno de los participantes. Muchos de estos proyectos se relacionan con el mejoramiento o mantenimiento de caminos, con la puesta en marcha de ecotecnologías, con la rehabilitación de sus ecosistemas, además de realizar talleres o cursos de capacitación que consideran necesarios para el mejoramiento comunitario, tales como: cursos alfabetización, capacitación jurídica, talleres sobre género, etc.

\section{Los maseual y sus organizaciones colectivas}

Cuetzalan del Progreso es un municipio poblano ubicado en el centro de México. Este municipio colinda al norte con Jonotla y Tenampulco, al este con Ayotoxco de Guerrero y Tlatlauquitepec, al sur con Zacapoaxtla y al oeste con Zoquiapan. Su superficie territorial es de 181.73 kilómetros cuadrados, integrado por 162 localidades. Cuetzalan está constituido por la cabecera municipal del mismo nombre y ocho juntas auxiliares²: San Andrés Tzicuilan, San Miguel Tzinacapan, Zacatipan, Reyeshogpan, Xocoyolo, Yohualichan, Yancuitlalpan, Xiloxochico (POET, 2010).

2 "[...] a nivel comunitario dentro de Cuetzalan, la instancia de poder político regional en la cual se organizan los pueblos son las Juntas Auxiliares, las cuales han venido desarrollándose como un órgano político entre las comunidades indígenas de esta región, conglomerando los barrios, rancherías, ranchos y parajes" (Baltazar, 2004:43) 
La topología natural hace que tenga alturas que van desde los 200 a los 1200 metros sobre el nivel del mar, su clima es húmedo-cálido y muy lluvioso. La flora característica de la zona se desarrolla principalmente en el llamado bosque tropical perennifolio, se distingue por la presencia de bastos cafetales, que representan el eje principal de la economía regional, también cuentan con otros productos tales como: leguminosas, frutas cítricas, pimientos, zapotes, encinos, robles, entre otros. La región está conformada por pueblos indígenas: nahuas, totonacos, tepehuas y otomíes, así como de población mestiza; la cual ascendió en 2010 a 45,781 habitantes, de los cuales 80 por ciento se identificó como nahua (INEGI, 2010).

Los nahuas del municipio de Cuetzalan se autodenominan "maseualmej" en plural o "maseual" en singular, que quiere decir "campesinos" (Linsalata, 2017). La identidad maseual es una herencia cultural que data de la época prehispánica. Su cosmovisión está íntimamente relacionada con la tierra y el cosmos. Las relaciones sociales entre los maseual dan un lugar preponderante a las relaciones de parentesco, el compadrazgo lleva implícito el fortalecimiento de los lazos familiares. Las celebraciones religiosas o fiestas patronales retroalimentan las relaciones sociales por lo cual tienen un lugar importante dentro de la comunidad (Armenta, 2016).

A finales del siglo XX, la Sierra Norte de Puebla fue parte de las políticas de desarrollo orientadas a impulsar la modernización de la agricultura (1970-1976). El Instituto Mexicano del Café (Inmecafé) fue el encargado de esta encomienda enfocando sus esfuerzos principalmente en tres estados de la República Mexicana: Oaxaca, Guerrero y Puebla, el objetivo principal era conformar unidades económicas de productores de café (UEPC) a las cuales se les dotaría de los insumos necesarios para producir y al mismo tiempo proporcionarles los canales de comercialización. Los "paquetes tecnológicos" consistían en fertilizantes, semillas, asesorías por parte de ingenieros agrónomos y acceso a créditos. Las directrices con las que se llevó a cabo esta política quitaban la libertad de decisión a los productores, los cuales tenían que cumplir con el cometido de hacer eficiente la producción de café a partir de la modalidad de monocultivos.

Con el paso del tiempo esto trajo repercusiones de tipo socioambiental, el uso de los agroquímicos derivó en la contaminación y erosión de sus tierras, así como en la dependencia económica y de insumos para la producción, agregando además los impactos que producía la variación de los precios internacionales del café tanto en la producción como en la comercialización. Esto fue un claro reflejo de la manera en la cual las políticas impuestas llevaban al campesinado a la proletarización (Palerm, 2008). Sin embargo, en la década de los setentas diversos eventos desembocaron en la movilización de las comunidades indígenas en la Sierra, uno de estos eventos fue el hartazgo por los bajos precios a los que se comercializaban sus productos agrícolas además del incremento de los precios de la canasta básica. Las acciones que llevaron a cabo para hacer frente a esta situación fue organizarse entre dos juntas auxiliares (San Miguel Tzinacapan y Xiloxochico) para comercializar conjuntamente sus productos fuera del municipio de Cuetzalan y a su vez conseguir productos de la canasta básica a precios razonables (Beaucage, 2012; Mejía et al., 2001)

La organización colectiva fue una de sus fortalezas para plantear estrategias que les permitieran hacer frente a las problemáticas que los aquejaban. Fue así como en 1977 se fundó la Cooperativa Agropecuaria Regional “Tosepan Titataniske” (CARTT). Dicha cooperativa se transformó en 1980 en la Sociedad Cooperativa Agropecuaria Regional “Tosepan Titataniske" Unidos Venceremos (SCARTT), la cual organizó el abasto de productos básicos y la comercialización de productos. Los pequeños productores identificaron que uno de los mayores problemas que tenían era que los particulares mestizos acaparaban la comercialización de sus productos (Mejía et al., 2001). 
"Los cambios económicos en la comercialización de los productos agrícolas de la región, desembocaron en cambios politicos, sociales y culturales dentro de las esferas étnicas del municipio de Cuetzalan. La población mestiza que controlaba la comercialización de estos productos hacia afuera de la región y abastecía de insumos, tuvo que cambiar sus actividades productivas ante el duro golpe que represento el empoderamiento de la cooperativa Tosepan" (Beaucage, 2012:35).

Los cambios económicos y sociopolíticos que trajo consigo su proceso organizativo a través de la cooperativa no impidieron que se siguieran reproduciendo patrones de discriminación y obstaculización de sus emprendimientos por parte de los grupos mestizos con la anuencia de las autoridades municipales y estatales. Sin embargo, lograron superar esas vicisitudes ya que el buen funcionamiento de la cooperativa derivó en el respaldo por parte de los representantes de la autoridad federal en Puebla (Beaucage, 2012).

La cooperativa conformada por indígenas nahuas y totonacos poco a poco se fortaleció a través de la toma de decisiones consensuada entre sus miembros, dejando atrás la estructura vertical impuesta por parte de los gobiernos municipal, estatal y federal, que los encaminaba a la dependencia económica. La conformación de la cooperativa les permitió generar su propia agenda de trabajo definida a partir de sus propias necesidades en el afán del beneficio individual-familiar y comunitario.

La discusión en asambleas sobre las problemáticas que inquietaban a los miembros de la cooperativa Tosepan ${ }^{3}$ aumentaron al paso del tiempo, al inicio las controversias se centraron en sus actividades productivas, no obstante, se incorporaron inquietudes de los miembros por proveerse de mejores calidades de vida, frente a la discriminación que sufrían por parte de la población mestiza con poder económico y político de la cabecera municipal. El poder económico que la cooperativa logró les permitió hacer frente al despojo de tierras y a la monopolización del comercio que los mestizos ejercieron durante siglos, lo que forjó las relaciones de clase en el territorio cuetzalteco (Hernández, 2018), razón por la cual, decidieron involucrarse en las estructuras formales de la política para elegir autoridades municipales en la región. A través de talleres se informó a los miembros de la cooperativa y a la población campesinoindígena en general sobre los derechos humanos y colectivos que les reconocían las leyes federales y estatales. Se crearon redes internas de productores, con académicos y universidades, otros colectivos regionales, nacionales e internacionales para comercializar productos agropecuarios, artesanías y enseres domésticos. Estas mismas redes les facilitaron información para gestionar apoyos gubernamentales y de organismos no gubernamentales para mejorar la forma en la que vivían, sin perder la esencia maseual.

Las mujeres indígenas-campesinas solicitaron a la cooperativa Tosepan la necesidad de impulsar proyectos específicos de apoyo para impulsar la comercialización de artesanías a través de la Formación de la Comisión Regional de Artesanas (CRA). “Entre 1987 y 1990 se inicia el proceso de crecimiento y con ritmos acelerados de trabajo, ya que mujeres de comunidades de este municipio y de otros aledaños, solicitan integrarse a la organización" (Mejía et al., 2001). Posteriormente se generaron conflictos internos y en su relación con la SCARTT.

\footnotetext{
3 La Unión Tosepan la integran 290 comunidades en 22 municipios de la Sierra Norte de Puebla, sumando 22 mil familias de origen tanto nahua como totonaco. La cooperativas que integran la Unión son: Tosepan Titataniske (agropecuaria), Tosepan Kali (servicios de hospedaje y turísticos), Toyektanemililis (materiales de construcción), Tosepan Pajti (servicios de salud), Tosepantomin (cooperativa de ahorro y préstamo), Tosepan Ojtasentekitinij (aprovechamiento del cultivo del bambú), Tosepansiuamej (mujeres artesanas), Maseual Xicaualis (servicios sociales). Las actividades productivas, de capacitación, educativas y culturales que realizan se organizan en programas cuya finalidad es mejor la calidad de vida y son: Orgánicos (desarrollo de sistemas de cultivo en armonía con la naturaleza y producción de alimentos de calidad libre de contaminantes), Pisilnekmej (proyecto productivo de miel virgen de abeja sin aguijón), Kaltaixpetaniloyan (capacitación continua en técnicas productivas y administrativas, de conciencia económica, sociopolítica, étnica, medioambiental y de genero para los miembros de las cooperativas que integran la Unión), Tosepan Kalnemachtiloyan (proyecto educativo de niños y jóvenes) y Nahua (proyectos de fortalecimiento y enseñanza de la lengua materna) (Armenta, 2016).
} 
Las mujeres consideraron que, en las asambleas de la cooperativa sus propuestas no eran escuchadas ni valoradas, razón por la cual tomaron la decisión de crear una organización de mujeres artesanas. Fue en 1992 que surgió la organización Maseual Siuamej Mosenyolchicauanij S.S.S., que significa mujeres indígenas unidas que se apoyan, sociedad de solidaridad social, cuya meta principal ha sido implementar actividades que mejoren la calidad de vida de sus miembros mediante proyectos productivos y de desarrollo humano ${ }^{4}$, bajo una visión femenina de lo que es necesario e indispensable en el bienestar personal, en el hogar y en la comunidad. La organización está integrada por comités y tiene presencia en las localidades de San Andrés Tzicuilan, San Miguel Tzinacapan, Pepexta, Xiloxochico, Chicueyaco y Cuauhtamazaco (Maseual Siuamej Mosenyolchicauanij, 2015; Mejía et al., 2001 y Carcaño, 2013).

Los colectivos indígenas y populares que han surgido en los últimos cincuenta años en la Sierra Norte de Puebla, en particular la cooperativa Tosepan y la organización Maseual Siuamej, luchan por proveerse de ingresos y empleos dignos y justos que les proporcionen bienestar material, que les permita permanecer ${ }^{5}$, cuidar y proteger su territorio. A través de estas organizaciones la población campesino-indígena de la región ha obtenido tanto poder económico, como poder político en pro de crear y mejorar sus condiciones de producción y reproducción social. Sus proyectos han ido desde el emprendimiento de acciones productivas en el sector primario hasta penetrar en el sector de servicios turísticos, alguna vez controlados por la población mestiza.

A través de la organización social, los maseual se allegaron de servicios públicos y privados como médicos, educativos, de caminos, transporte y financieros, entre otros, los cuales ajustaron a sus necesidades culturales y sociales. Estos servicios les fueron acaparados durante buena parte del siglo XX por los pobladores mestizos de la cabecera municipal. Los pobladores indígenas organizados recuerdan cómo las autoridades municipales les negaban los apoyos provenientes de programas estatales y federales por su condición indígena y por la distancia física entre las juntas auxiliares y las demás comunidades. Los maseual aprendieron a establecer redes con otras organizaciones colectivas, indígenas y no indígenas, universidades y organismos no gubernamentales, que coadyuven la expansión de la comercialización sus productos y les permita abastecerse de los insumos que no producen a precios razonables.

El ideario de bienestar que se encuentra inmerso en sus estrategias productivas está en sintonía con su cosmovisión indígena, basada en el respeto y cuidado a la naturaleza y en relaciones sociales que priorizan la solidaridad y la reciprocidad sobre los intercambios puramente mercantilistas, pues consideran que tienen una responsabilidad con los consumidores de sus productos. La idea de bienestar social de los maseual, limitada por las restricciones mismas de la naturaleza, contribuye al desarrollo nacional y mundial, pues estas mismas actividades son replicadas, en esencia, pero con diferencias culturales, por otros grupos sociales alrededor del planeta (Barkin et al., 2011a). Por lo que, consideramos que el control social del excedente económico es consecuencia del control y la gestión colectiva del territorio, al discutir, consensuar y cumplir las normas de apropiación de los insumos que proporciona la naturaleza.

\section{Los retos de los maseual}

La Sierra Norte de Puebla, en los últimos años se ha visto amenazada por diversos proyectos minero-energéticos que afectarían sus tierras y aguas. La movilización

4 La organización construyó el hotel Taselotzin en 1995, con el propósito de proporcionar un espacio de descanso a los turistas que visitaban la cabecera municipal, bajo un concepto ecológico y cultural del significado de ser maseual, donde dieran a conocer y comercializaran sus productos artesanales y de medicina herbolaria, así como un espacio para el intercambio de ideas y la retroalimentación.

5 El inicio de la migración de los nahuas con dirección hacia Estados Unidos se presenta hacia la segunda mitad de la década de los ochenta (López, 2015). 
colectiva de estas comunidades por la defensa del territorio está asociada con la construcción de alternativas ante los embates de las lógicas de acumulación de capital. Para hacer frente han conformado una red de colectivos entre los que se encuentran la organización “Tosepan Titataniske” y "Maseualsiuamej Monsenyolchicauanij”, que acompañan los procesos de organización y resistencia de las poblaciones afectadas con el fin de detener la ofensiva de los proyectos extractivos (Carcaño, 2017).

Las estrategias que han llevado a cabo para la defensa de territorio han sido: información a la población por medio de las asambleas comunitarias, así como encuentros con otros pueblos en resistencia para intercambiar experiencias contra los proyectos mineros (Fuente et al., 2016). Una herramienta jurídica fundamental que han utilizado en su lucha ha sido la elaboración del ordenamiento territorial que les ha permitido reglamentar los diversos usos del territorio, así como poner límite a la apropiación privada de los bienes colectivos (Linsalata, 2017).

La población organizada del municipio de Cuetzalan, tanto indígena como no indígena, crearon el Programa de Ordenamiento Ecológico Local del Territorio del municipio de Cuetzalan del Progreso (POET), donde la participación de la cooperativa Tosepan y de la organización Maseual Siuamej, fue relevante, al lograr que la Benemérita Universidad Autónoma de Puebla, coordinara y respaldara este programa de ordenamiento territorial. Este ordenamiento territorial se realizó con la participación informada de la población, a través de talleres y asambleas, donde se recolectó información sobre el territorio, su capacidad geofísica y el proyecto social comunal de vida de sus pobladores. Gracias al aval de la Universidad poblana se logró el consenso político estatal necesario para que el Programa de Ordenamiento Ecológico Local del Territorio del municipio de Cuetzalan del Progreso (POET), fuese publicado en el periódico oficial del Estado Libre y Soberano de Puebla, el día 3 de diciembre de 2010, cuya publicación lo convirtió en una normativa estatal que establece los usos del territorio.

El proceso participativo de construcción colectiva del ordenamiento territorial comenzó el 30 de mayo de 2009, en el cual participaron tanto el Ayuntamiento Constitucional de Cuetzalan, colectivos indígenas y no indígenas, así como académicos de la Benemérita Universidad Autónoma de Puebla (POET, 2010). El objetivo principal del POET fue elaborar un elemento jurídico que diera certeza a los habitantes del municipio para determinar los usos del suelo, de acuerdo con sus aptitudes geofísicas, y poder implementar actividades productivas de bajo impacto ecológico, al mismo tiempo que, esta normatividad coadyuvaría a conciliar los intereses privados de los sectores productivos y a mantener un equilibrio ecosistémico del territorio (POET, 2010).

La biodiversidad que impera en el territorio cuetzalteco es resultado de siglos de intercambios metabólicos, que los nahuas y totonacos han tenido con su territorio. A estas costumbres y tradiciones se han sumado el empoderamiento social, económico y político, que, en las últimas décadas, les ha permitido pugnar por el cuidado y protección de su hábitat, a la par que se han autogenerado bienestar. Los habitantes del municipio de Cuetzalan, en particular estas poblaciones nahuas y totonacas organizadas, son parte de la creación, ejecución y vigilancia de la normativa y de los proyectos públicos que se ejecutan en su territorio, bajo estructuras de democracia participativa. El control y la gestión del territorio se ejerce a través del dialogo, el trabajo colectivo y la disputa, tanto interna como externa, mediante las asambleas, el tequio y la lucha, para defender lo más preciado de estas culturas "la vida".

Las poblaciones campesinas e indígenas con un fuerte arraigo al territorio, que viven respetando los límites que la naturaleza les impone, en una vida social comunitaria, luchan en la cotidianidad y permanentemente por su sobrevivencia como grupos 
sociales, siempre buscando mejores calidades de vida para sí, para los suyos y para las futuras generaciones (Beaucage, 2012). El territorio proporciona los insumos indispensables para la vida; su degradación implica destruir los cimientos que le dan sentido al grupo social que lo habita, pues pone en jaque su propia existencia. El territorio como espacio social se fortalece y se renueva a cada momento en que los pobladores de este toman decisiones en colectividad sobre sus problemáticas y sus posibles soluciones.

Por lo que consideramos que quién crea y modifica las normativas de apropiación, circulación, distribución y consumo de los bienes y servicios que proporciona la naturaleza ejerce control sobre los territorios, a pesar de la imposición misma que a través de las estructuras del Estado-Nación desplieguen las fuerzas del Capital. Razón por la cual toda lucha y defensa de los territorios parte de la disputa misma de su control por un grupo organizado que tenga sentido de pertenencia. La defensa de los territorios implica defender formas de vida contrapuestas a la idea crecimiento ilimitado en un planeta finito. Como lo argumentan los pueblos campesino-indígenas es una lucha entre la vida y la muerte.

\section{Conclusiones}

Los maseual del municipio de Cuetzalan, en particular los miembros de la cooperativa Tosepan o de la organización Maseual Siuamej, nos transmiten la posibilidad de seguir proyectando aún un mundo donde se pueda custodiar una memoria ancestral dirigida a la dignidad y al respeto con el entorno. Estos proyectos de memoria y transformación son eminentemente colectivos y los impulsan a gestar proyectos productivos donde aplican sus conocimientos ancestrales bajo vertientes que pugnan por el equilibrio ambiental y social. Las estrategias que estas organizaciones colectivas han llevado a cabo son parte de la respuesta a los procesos de exclusión que han vivido históricamente y que con el paso del tiempo se han agudizado debido a la lógica depredatoria de acumulación de capital. Es pues una estrategia de resistencia desde la cual estos pueblos han imbricado capacidad de empoderamiento y resiliencia.

La gran biodiversidad de la Sierra Norte de Puebla está ligada a la riqueza biocultural de la región. La relación que estas comunidades guardan con sus ecosistemas, la forma en que los aprovechan y transforman cotidianamente, es reflejo de una interrelación milenaria de hombres y mujeres con la naturaleza, permitiéndoles recrear procesos a través de los cuales logran la utilización de sus ecosistemas acorde con su cosmovisión ancestral. El control del territorio se proyecta más allá de lo económico, garantizando además el cuidado de la memoría ancestral y la revalorización de su cultura.

El estudio de la organización colectiva de las mujeres indígenas a través de la "Maseualsiuamej Monsenyochicahuanij" ha sido importante para entender estos pactos sociales que aunque antiquísimos se renuevan permanentemente. La puesta en marcha de proyectos productivos definidos y dirigidos por las mujeres ha servido para recuperar conocimientos tradicionales, para reforzarlos y para transmitirlos a las siguientes generaciones. El control que las mujeres han tenido de los excedentes derivados de los proyectos productivos ha reforzado su participación comunitaria y a la vez ha beneficiado tanto a la comunidad como a sus familias. Hay que indicar además que este uso colectivo de los excedentes económicos les permite su movilización para emplearlos en la defensa, cuidado y protección de sus territorios, así como sirven de sustento para generar proyectos alternativos de producción (como hemos emprendimientos de eco-turismo), lo que les permite mejorar su bienestar bajo un sentimiento de dignidad y auto-confianza, que se debe también valorar, más allá de las consideraciones puramente económicas.

A partir de lo que transmiten cabe señalar que uno de los cambios que los tiempos actuales requieren no es sencillamente implantar procesos de adaptación ecológica 
sino un debate más profundo en torno a las posibilidades de erigir un sistema de producción, que no dañe y mutile procesos de dignidad social, pactos fraternos de solidaridad y memorias históricas a las que es preciso preservar, a riesgo de generar condiciones de catástrofe y perplejidad cultural y comunitaria.

\section{Referencias Bibliográficas}

Aragón, O. (2007), Los sistemas jurídicos indígenas frente al derecho estatal en México. Una defensa del pluralismo jurídico. Boletín Mexicano de Derecho Comparado, nueva serie, año XL, número 118, enero-abril, pp. 9-26

Armenta, W. (2016). Acumulación de capital extra-económica en el México rural. Cuetzalan del Progreso, Puebla. Tesis doctoral en Ciencias Económicas, Universidad Autónoma Metropolitana.

Artigas P., E. (2012). Convergencias y divergencias en las nociones sobre territorio, asentamiento y comunidad, Revista Caribeña de Ciencias Sociales, octubre., pp. 24-36

Baltazar, S. (2004). Una mirada a la participación política de las mujeres nahuas de Cuetzalan. Tesis para obtener el grado de Licenciada en Etnología. Escuela Nacional de Antropología e Historia. México.

Baran, P. A. (1987 [1957]). La economía política del crecimiento. México, Fondo de Cultura Económica.

Barkin, D. et al. (2011a). La economía ecológica y solidaria: Una propuesta frente a nuestra crisis. Sustentabilidades, $\mathrm{N}^{\circ}$, pp. 26-36

Barkin, D. et al. (2011b). Capacidad social para la gestión del excedente: la construcción de sociedades alternativas. En F. Novelo. La UAM ante la sucesión presidencial. Universidad Autónoma Metropolitana

Barkin, D., et. al. (2009). Tradición e innovación. Aportaciones campesinas en la orientación de la innovación tecnológica para forjar sustentabilidad. Trayectorias, Vol. 11, Número 29, julio-diciembre, pp. 39-54.

Baronnet, B., et al, coordinadores (2011). Luchas "muy otras". Zapatismo y autonomía en las comunidades indígenas de Chiapas, UAM-Xochimilco, CIESAS y Universidad Autónoma de Chiapas.

Beaucage, P. (2012). Cuerpo, cosmos y medio ambiente entre los nahuas de la Sierra Norte de Puebla. Una aventura en antropología, Taller de Tradición Oral del CEPEC, Instituto de Investigaciones Antropológicas - UNAM, Dialog. Red de Investigación y de Conocimientos Relativos a los Pueblos Indígenas y Unión de Cooperativas Tosepan Titataniske.

Boege, E. (2011). Las regiones bioculturales prioritarias para la conservación y desarrollo en México. En A. Argueta, Corona y Hersch (coord.). Saberes colectivos y diálogo de saberes en México. México. Universidad Nacional Autónoma de México. Centro Regional de Investigaciones Multidisciplinarias.

Carcaño, E. (2017). Democracia y medio ambiente: Historia de un desencuentro. La sierra norte de Puebla y los megaproyectos extractivos. En J. Russo. Democracias y ciudadanías en América Latina. Ensayos en honor de Francisco Delich. México. Editorial. Eón.

Carcaño, E. (2013). Las mujeres indígenas en la Nueva Ruralidad Comunitaria (NRC) y su implicación en la generación de excedentes. El caso de la organización Masehualsihuamej Monsenyolchicahuanij, Tesis doctoral en ciencias económicas, Universidad Autónoma Metropolitana.

Carlsen, L. (1999). Autonomía indígena y usos y costumbres: la innovación de la tradición. Revista Chiapas No. 7. Recuperado de: www.revistachiapas.org/No7/ch7cecena.html

De Grammont, H. y Martínez, L. (coord.) (2009). La pluriactividad en el campo latinoamericano. FLACSO. Ecuador.

Escobar, A. (2009). Una minga para el postdesarrollo. América Latina en Movimiento, año XXXIII, II época, junio, $N^{\circ} 445$.

Fuente M. et al. (2016). La nueva ruralidad comunitaria como estrategia de gobernanza local frente al paradigma neoliberal. En J. A. Rodríguez, L. Álvarez, D. Tagle, J. Coronado. 
Desarrollo desde lo local y dinámicas territoriales. México. Universidad de Guanajuato, Fontamara.

Hernández, F. (2018). Los defensores de la vida contra los proyectos de muerte: Resistencias y Articulaciones frente a la industria extractiva en la Sierra Norte de Puebla. Bajo el Volcán, vol. 18, núm. 28, marzo-agosto, pp. 109-143. Benemérita Universidad Autónoma de Puebla. Puebla. ISSN: 8170-5642

Instituto Nacional de Estadística, Geografía e Informática (INEGI), (2020). Estadísticas a propósito del día internacional de los pueblos indígenas. Recuperado de: https://www.inegi. org.mx/contenidos/saladeprensa/aproposito/2020/Indigenas2020.pdf

Instituto Nacional de Estadística, Geografía e Informática (INEGI), (2010). Conteo de Población y vivienda 2010, tabulados básicos. Recuperado de: http://www.inegi.org.mx

Lefebvre, H. (1969). State, space, world. Selected essays, University of Minnesota Press, London, England.

Linsalata, L. (2017). De la defensa del territorio maseual a la reinvención comunitario-popular de la política: crónica de una lucha. Estudios Latinoamericanos, Nueva Época, Núm. 40, juliodiciembre, pp. 117-136.

López, F. (2005). Territorios indígenas y conflictos agrarios en México. Estudios Agrarios, Núm.2 pp. 85-118

López y Rivas, G. (2012). Autonomías de los pueblos indios en México. México. Ed. Armonía.

López, M. (2015). Remesas, migración y desarrollo de las comunidades indígenas del Estado de Puebla. En G. Roldán y C. Sánchez. Remesas, migración y comunidades indígenas de México. México, D.F. Universidad Nacional Autónoma de México, Instituto de Investigaciones Económicas.

Manzo, C. (2011). Comunalidad. Resistencia Indígena y Neocolonialismo en el Istmo de Tehuantepec (siglos XVI-XXI), UACI, UCIZONI y Centro de Estudios Antropológicos Ce-Acatl, A.C.

Martínez L., J. (2003). Comunalidad y Desarrollo, Conaculta-Culturas Populares e Indígenas y Centro de Apoyo al Movimiento Popular Oaxaqueño, A.C.

Maseual Siuamej Mosenyolchicauani (2015), Tejiendo nuestras vidas. Hilando nuestras historias, Cuetzalan del Progreso Puebla, julio.

Mejía S., et al., (2001). "Maseualsiuamej Monsenyolchicauanij” Mujeres indígenas que trabajan juntas y se apoyan. Sistematización del proceso de producción y comercializción artesanal. En P. Bonfil, B. Suárez. De la tradición al mercado microempresas de mujeres artesanas. México. Editorial GIMTRAP.

Núñez, V. (2010). Los procesos de despojo en territorios indígenas durante el patrón de acumulación neoliberal: su confrontación con la lógica indígena de los maya-tojolabales, Tesis doctoral en desarrollo rural, UAMX.

Palerm, A. (2008). Antropología y Marxismo, Clásicos y Contemporáneos en Antropología. México. CIESAS, UAMI y la Universidad Iberoamericana.

Participación de la Comisión Sexta del EZLN (2015), El Pensamiento Crítico Frente a la Hidra Capitalista, UAM-Xochimilco.

Pérez, S. (2017). Recursos bióticos en la atención de la enfermedad. Temas Antropológicos, Vol. 39, Núm. 1, marzo, Universidad Autónoma de Yucatán, pp. 33-54.

Porto-Goncalves, C. W. (2009), Del desarrollo a la autonomía: La reinvención de los territorios, América Latina en Movimiento. año XXXIII, II época, junio, Nº 445. Recuperado de: http:// www.alainet.org/es/revistas/445.

Programa de ordenamiento ecológico territorial del municipio de Cuetzalan del Progreso, POET (2010). Periódico Oficial del Gobierno Constitucional del Estado de Puebla, Número 2 Séptima Sección, Tomo CDXXVIII, 3 de diciembre. Recuperado de: http://www.semarnat.gob. $\mathrm{mx} /$ archivosanteriores/temas/ordenamientoecologico/Documents/documentos\%20 decretados/actualizacion_2013/ordenamiento_cuetzalan.pdf.

Rodríguez W., C. A. (2010). Defensa comunitaria del territorio en la zona central de México, Enfoques teóricos y análisis de experiencias. México. Juan Pablos Editor. 
Registro Agrario Nacional (RAN), (2020). Padrón e Historial de Núcleos Agrarios. Recuperado de: https://phina.ran.gob.mx/consultaPhina.php

Rovira, G. (2002), Mujeres de maíz, Ediciones Era.

Toledo, V. M. (2009). Ecología política sustentabilidad y poder social en Latinoamérica. América Latina en Movimiento año XXXIII, II época, junio, Nº 445, pp. 11-27

Toledo et al. (2008), La memoria biocultural. La importancia ecológica de las sabidurías tradicionales, Icaria editorial, Barcelona, España.

Villoro, L. (1999). De la libertad a la comunidad. México, D.F. Ariel y Tecnológico de Monterrey. 